"This is a post-peer-review, pre-copyedit version of an article published in Antonie van Leeuwenhoek. The final authenticated version is available online at: http://dx.doi.org/10.1007/s10482-019-01349-6",

\title{
Micromonospora orduensis sp. nov., isolated from deep marine sediment
}

\section{Aysel Veyisoglu ${ }^{1 * \dagger}$, Lorena Carro ${ }^{2 *}$, Demet Cetin ${ }^{3}$, Jose M. Igual ${ }^{4}$, Hans-Peter Klenk ${ }^{5}$,}

\section{Nevzat $\operatorname{Sahin}^{6 \dagger}$}

${ }^{1}$ Vocational School of Health Services, Department of Medical Laboratory Techniques, Sinop University, 57000, Sinop, Turkey

${ }^{2}$ Departamento de Microbiología y Genética, Edificio Departamental, Campus Miguel de Unamuno, Universidad de Salamanca, 37007, Salamanca, Spain

${ }^{3}$ Division of Science Education, Department of Mathematics and Science Education, Gazi Faculty of Education, Gazi University, 06500, Ankara, Turkey

${ }^{4}$ Instituto de Recursos Naturales y Agrobiología de Salamanca, Consejo Superior de Investigaciones Científicas (IRNASA-CSIC), c/Cordel de Merinas 40-52, 37008 Salamanca, Spain

${ }^{5}$ School of Natural and Environmental Sciences, Newcastle University, Ridley Building, Newcastle upon Tyne, NE1 7RU, UK

${ }^{6}$ Department of Molecular Biology and Genetics, Faculty of Art and Science, Ondokuz Mayis University, 55139, Samsun, Turkey

*These authors have participated equally to this work.

${ }^{\dagger}$ Authors for correspondence: Nevzat Sahin and Aysel Veyisoglu

Tel : +90 3623121919 - Ext: 54 52; +90 36827157 57- Ext: 3421

Fax: +9036245760 81; +903682715758

E-mail: nsahin@omu.edu.tr; aveyisoglu@ sinop.edu.tr 


\section{Abstract}

A novel actinobacterial strain, designated $\mathrm{S} 2509^{\mathrm{T}}$, was isolated from marine sediment collected by a dredge at a depth of $45 \mathrm{~m}$ along Melet River offshore of the southern Black Sea coast, Ordu, Turkey. The cell wall peptidoglycan of strain was found to contain mesodiaminopimelic acid and 3-OH-diaminopimelic acid. The whole cell sugars detected were arabinose, glucose, rhamnose, ribose and xylose. The diagnostic phospholipids of strain $\mathrm{S} 2509^{\mathrm{T}}$ were found to be diphosphatidylglycerol, phosphatidylethanolamine, phosphatidylinositol, a glycolipid and two unidentified phospholipids. The predominant

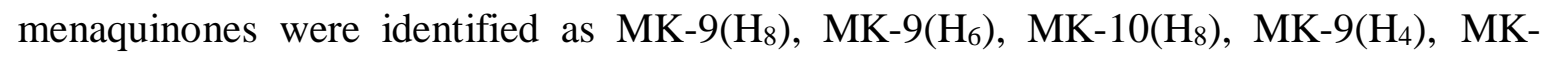
$10\left(\mathrm{H}_{4}\right)$ and $\mathrm{MK}-10\left(\mathrm{H}_{6}\right)$. The major cellular fatty acids were found to be iso- $\mathrm{C}_{16: 0}$, iso- $\mathrm{C}_{15: 0}$ and 10-methyl $\mathrm{C}_{17: 0}$. The taxonomic position of the strain was established using a polyphasic approach, showing that $\mathrm{S} 2509^{\mathrm{T}}$ strain belongs to the genus Micromonospora. Phylogenetic analysis based on the $16 \mathrm{~S}$ rRNA gene sequence of strain $\mathrm{S} 2509^{\mathrm{T}}$ showed that it is closely related to the type strain of Micromonospora chokoriensis DSM $45160^{\mathrm{T}}(99.37$ $\%$ sequence similarity), and phylogenetically clustered with Micromonospora inaquosa $\mathrm{LB}^{\mathrm{T}}{ }^{\mathrm{T}}(99.37 \%)$, Micromonospora lupini Lupac $14 \mathrm{~N}^{\mathrm{T}}(99.16 \%)$, Micromonospora violae NEAU-zh8 ${ }^{\mathrm{T}}(99.23 \%)$ and Micromonospora taraxaci NEAU-P5 ${ }^{\mathrm{T}}(99.03 \%)$. The phylogenetic analysis based on the gyrB gene sequence of strain $\mathrm{S} 2509^{\mathrm{T}}$ confirmed its close relationship with $M$. chokoriensis $\mathrm{JCM} 13247^{\mathrm{T}}$ (96.5\% sequence similarity). Whole genome sequences confirmed by digital DNA-DNA hybridization analysis that the strain $\mathrm{S} 2509^{\mathrm{T}}$ represents a novel species in the genus Micromonospora, for which the name Micromonospora orduensis sp. nov. is proposed. The type strain is $\mathrm{S} 2509^{\mathrm{T}}$ (=DSM $45926^{\mathrm{T}}$ $\left.=\operatorname{KCTC} 29201^{\mathrm{T}}\right)$.

Keywords: Micromonospora, polyphasic taxonomy, marine sediment, 16S rRNA gene, gyrB gene 


\section{Introduction}

The genus Micromonospora was described by Ørskov in 1923 (Kawamoto 1989), and at the time of writing, the genus comprised 84 species with validly published names (www.bacterio.net/micromonospora.html). Micromonosporae are frequent inhabitants of aquatic habitats worldwide where they participate in the decomposition of cellulose, chitin and lignin (Cross et al. 1989; Gullo et al. 2006). Micromonospora strains have been isolated from water samples from streams, rivers and lakes, from lake mud, river sediments, beach sands, littoral sediments and deep marine sediments (Cross et al. 1989; Goodfellow and Williams 1983; Jensen et al. 2005). Micromonosporae have been found to be the dominant actinomycetes group in a range of aquatic environments, particularly in the deeper mud layers, as well as in deep sea sediments (Rusnak et al. 2001; Mincer et al. 2002). In recent years many Micromonospora species have been isolated from sea sediment, as exemplified by Micromonospora fluostatini (Phongsopitanun et al. 2015), Micromonospora yasonensis (Veyisoglu et al. 2016), Micromonospora profundi (Veyisoglu et al. 2016) and Micromonospora globispora (Carro et al. 2019). In the present study, we describe a novel species isolated from a Black Sea deep sediment. The resultant data showed that isolate $\mathrm{S} 2509^{\mathrm{T}}$ represents a novel Micromonospora species for which the name Micromonospora orduensis sp. nov. is proposed.

\section{Materials and methods}

Isolation, maintenance and cultural conditions of strains

Strain S2509 ${ }^{\mathrm{T}}$ was isolated from marine sediments collected by a dredge at a depth of 45 $\mathrm{m}$, offshore of the Melet river, Turkey (GPS coordinates for sampling site are $41^{\circ} 00.353^{\prime}$ $\mathrm{N}$ and $\left.37^{\circ} 57.489^{\prime} \mathrm{E}\right)$. The sediment samples were stored at $-20{ }^{\circ} \mathrm{C}$ until examined using a standard dilution plate method. The diluted sediment suspensions were inoculated on SM3 
medium (Gauze's medium 2) [20 g casamino acids, $20 \mathrm{~g}$ soluble starch, $4 \mathrm{~g}$ yeast extract, $15 \mathrm{~g}$ agar, $\mathrm{pH}$ 7.2-7.4 per litre distilled water] (Tan et al. 2006) supplemented with filter sterilised cycloheximide $(50 \mu \mathrm{g} \mathrm{ml}-1)$, nalidixic acid $(10 \mu \mathrm{g} \mathrm{ml}-1)$, novobiocin $(10 \mu \mathrm{g} \mathrm{ml}-1)$ and nystatin $(50 \mu \mathrm{g} \mathrm{ml}-1)$, incubated at $30{ }^{\circ} \mathrm{C}$ for 30 days. The strain was isolated as a pure culture and maintained on yeast extract-malt extract agar [International Streptomyces Project medium 2 [ISP 2]; (Shirling and Gottlieb 1966)] slopes at room temperature and preserved as suspensions of mycelial fragments and spores in glycerol $(25 \%, \mathrm{v} / \mathrm{v})$ at -80 ${ }^{\circ} \mathrm{C}$. Micromonospora chokoriensis DSM 45160T (Ara and Kudo 2007) was obtained from DSMZ (German Collection of Microorganisms and Cell Cultures) and cultured under comparable conditions as a reference strain.

Morphological, cultural, physiological and biochemical characteristics

The micromorphological properties of strains were determined by examining gold coated dehydrated specimens of 43-days cultures N-Z-Amine (DSMZ Medium 554) using a JEOL JSM 6060 instrument. Cultural characteristics were determined after growth for 14 days at $30{ }^{\circ} \mathrm{C}$ as described by Shirling and Gottlieb (1966) on ISP 2, ISP 3, ISP 4, ISP 5, ISP 6 , ISP 7 and modified Bennett's agar (Jones 1949), Czapek's, nutrient and tryptic soy agar (Difco). ISCC-NBS Colour Name Charts Standard Samples No 2106 (Kelly 1964) was used to determine the colour of colonies and soluble pigments. Tolerance of various temperatures $\left(4,10,20,28,37,40,45,50\right.$ and $\left.55^{\circ} \mathrm{C}\right), \mathrm{NaCl}$ concentrations $(1-10 \mathrm{NaCl}$ $93(\mathrm{w} / \mathrm{v})$ at intervals of $1.0 \mathrm{NaCl}$ unit $)$ and $\mathrm{pH}(4,5,6,6.5,7,7.5,8,8.5,9,10,11$ and 12$)$ were determined on ISP 2 at $30{ }^{\circ} \mathrm{C}$ for 14 days; $\mathrm{KH} 2 \mathrm{PO} 4 / \mathrm{HCl}, \mathrm{KH} 2 \mathrm{PO} 4 / \mathrm{K} 2 \mathrm{HPO} 4$ and $\mathrm{K} 2 \mathrm{HPO} 4 / \mathrm{NaOH}$ buffer systems were used to maintain the $\mathrm{pH}$ values of the media. Utilisation of sole carbon sources was tested using ISP 9 (pH 9) (Shirling and Gottlieb 1966) and supplemented with a final concentration of $1 \%(\mathrm{w} / \mathrm{v})$ of the corresponding carbon source. Utilisation of amino acids as nitrogen sources was tested as described by 
Williams et al. (1983) supplemented with a final concentration of $0.1 \%(\mathrm{w} / \mathrm{v})$ of the nitrogen sources. The degradation tests were examined using the method described by Williams et al. (1983). Hydrolysis of arbutin, allantoin, aesculin, urea and nitrate were determined as described by Collins et al. (2004) and that of Tweens (40 and 80) according to the method of Nash and Krent (1991).

\section{Chemotaxonomic characteristics}

Biomass for chemical studies was obtained by growing strain S2509T in GYM medium (DSMZ Medium 65) in shake flasks (200 r.p.m.) at $30^{\circ} \mathrm{C}$ for 14 days. Cells were harvested by centrifugation, washed twice with sterile distilled water and freeze-dried (Minnikin et al. 1984). Whole cell sugar composition was prepared according to Lechevalier and Lechevalier (1970) and analysed by thin layer chromatography (Staneck and Roberts 1974). Standard thin layer chromatographic procedures were used to establish the chemotaxonomic profiles of the strains, including the determination of the isomers of diaminopimelic acid (A2pm) (Staneck and Roberts 1974), predominant isoprenologues (Collins 1985; Kroppenstedt 1985), diagnostic sugars and polar lipids, using the procedure of Minnikin et al. (1984). Cellular fatty acids were extracted, methylated and separated by gas chromatography using an Agilent Technologies $6890 \mathrm{~N}$ instrument, fitted with an autosampler and a 6783 injector, according to the standard protocol of the Sherlock Microbial identification (MIDI) system (Sasser 1990; Kämpfer and Kroppenstedt 1996); the fatty acid methyl ester peaks were quantified using the TSBA 5.0 database.

DNA preparation, amplification and determination of 16S rRNA and gyrB gene sequences Genomic DNA extraction, PCR-mediated amplification and 16S rRNA gene sequencing were performed as described by Chun and Goodfellow (1995), using an ABI PRISM 3730 XL automatic sequencer. The resultant $16 \mathrm{~S}$ rRNA gene sequences were aligned with 
corresponding sequences of representative type strains of the genus Micromonospora (retrieved from the EzBioCloud server; Yoon et al. 2017) by using CLUSTAL W in MEGA version 7.0 software (Tamura et al. 2013). PCR amplification and gyrB gene sequencing were carried out on strain S2509T using primers GYF1 and GYR3B, as described by Garcia et al. (2010). Phylogenetic analyses were carried out using the neighbour-joining (Saitou and Nei 1987), maximum-likelihood (Felsenstein 1981) and maximum-parsimony (Kluge and Farris 1969) algorithms from the MEGA version 7.0 software. Evolutionary distances were calculated using the Kimura two-parameter (Kimura 1980) and topologies of the resultant trees evaluated by bootstrap analyses (Felsenstein 1985) based on 1000 resamplings. Catellatospora citrea DSM 44097T (16S rRNA gene sequence GenBank accession number X93197) was used as the outgroup.

\section{Whole genome sequencing}

The genome of S2509T was sequenced using the Illumina HiSeq 2500 platform (250 p paired-end reads) at Microbes NG and analysed with a standard pipeline; to determine the closest available genome and mapping the reads against it Kraken and BWA mem software were used, respectively. SPAdes was used to generate a de novo assembly of the generated reads. VarScan was used for variant calling and MUMmer aligment to reorder and reorient the assembly relative to the reference genome. Prokka was used to perform an automated annotation. Genome base content was used to calculate GC content of the strain. Previously generated genomes were used for comparison (Carro et al., 2018). A whole genome phylogeny was generated using the TYGS server (http://tygs.dsmz.de) (MeierKolthoff and Göker, 2019). The whole genome sequence generated was used to determine OGRI values with respect to closely related type strains, including the digital DNA-DNA hybridization $(\mathrm{dDDH})$ value calculated using formula 2 of the GGDC web server available 
at http://ggdc.dsmz.de/ggdc.php\# and OrthoANI value using OAT version 0.93.1 (Lee et 148 al. 2016).

\section{Results and discussion}

Morphological observation of a 43-day-old culture of strain S2509T grown on N-Z-Amine agar revealed it had the typical characteristics of members of the genus Micromonospora. Strain S2509T was found to be non-motile and to bear single eliptical to oval spores $(0.4 \mathrm{x}$ $0.6 \mu \mathrm{m}$ ) with smooth surfaces on branched substrate hyphae without fragmentation (Fig. S1). Good growth was observed on ISP2, ISP3, modified Bennett's and tryptic soy agar; moderate growth was observed on ISP6 and nutrient agar; poor growth was observed on ISP4, ISP5, ISP7 and Czapek's agar. The colour of the colonies varied, from light orange to dark brown; dark brown on ISP 3, dark orange on ISP 2 and ISP7, light orange on ISP 4, ISP 5, ISP 6, modified Bennett's, nutrient, Czapek's and tryptic soy agars. No diffusible pigments were observed on any of the tested media, including ISP 6 and ISP 7 agars (Table $160 \mathrm{~S} 1)$.

Growth of strain S2509T was found to occur in the $\mathrm{pH}$ range 5-11 and 0-3\% $\mathrm{NaCl}(\mathrm{w} / \mathrm{v})$, with optimum growth at $\mathrm{pH} 7.0$ and $0 \% \mathrm{NaCl}(\mathrm{w} / \mathrm{v})$. Strain $\mathrm{S} 2509 \mathrm{~T}$ was found to grow at $28-40{ }^{\circ} \mathrm{C}$, optimally $\approx 30{ }^{\circ} \mathrm{C}$. Detailed physiological properties are shown in the species description and Table 1.

Cells of strain S2509T were observed to contain meso-diaminopimelic acid and 3-OHdiaminopimelic acid. Whole cell hydrolysates were found to contain arabinose, glucose, rhamnose, ribose and xylose. The phospholipid profile was found to contain diphosphatidylglycerol, phosphatidylethanolamine, phosphatidylinositol, a glycolipid and two unidentified phospholipids (Fig. S2). The predominant menaquinones detected were 
10(H4) (14.6\%) and MK-10(H6) (14.4\%). The cellular fatty acid profile was determined to be composed of iso-C16:0 (28.1\%), iso-C15:0 (17.0\%), 10-methyl C17:0 (12.0\%), anteisoC17:0 (7.9\%), C17:1w8c (5.9\%) and C17:0 (5.5\%) (0.4\%) (Table 2).

The almost complete 16S rRNA gene sequence of strain S2509T (1475 bp) was determined and deposited as KF494805 in the GenBank/EMBL/DDBJ databases. Based on the EzTaxon-e analysis, strain S2509T was affiliated to the genus Micromonospora positioned in an independent branch and clustered with M. chokoriensis DSM 45160T (99.37\%), Micromonospora inaquosa LB39T (99.37 \%), Micromonospora violae NEAU-zh8T (99.23 \%), Micromonospora lupini Lupac14NT (99.16 \%) and Micromonospora taraxaci NEAUP5T (99.03 \%) (Fig. 1 and Fig. S3), a relationship that was supported by the corresponding maximum-likelihood and maximum-parsimony analyses (Fig. S4 and Fig. S5), although with low bootstrap support.

The partial gyrB gene sequence obtained for strain S2509T (1131 nt) has been deposited in the GenBank/EMBL/DDBJ databases as KF818378. The gyrB sequence analysis showed that the strain S2509T forms an independent branch clustered with the type strains of M. chokoriensis DSM 45160T (96.5\%) and M. taraxaci NEAU-P5T (96.3\%), a relationship that was supported by the corresponding maximum-likelihood and maximum-parsimony analyses and by a high bootstrap value (Fig. 2 and Fig. S6). The phylogenetic analyses based on 16S rRNA gene and gyrB gene sequences confirmed that strain S2509T clustered together with the type strain of M. chokoriensis.

The draft genome sequence of the strain S2509T presents a genome size of $6898708 \mathrm{bp}$, comprised of 321 contigs, with 6,535 protein coding genes, 57 RNA (5 rRNA) and 256 pseudogenes. The N50 value is 40,544 and the DNA G+C content of strain S2509T was found to be $71.7 \mathrm{~mol} \%$. Whole enome phylogeny show S2509T forms independent branch and confirmed that M. chokoriensis DSM45160T and M. taraxaci DSM45885T are closely 
related type strains, and that the strain is also closely related to M. lupini Lupac 08 (Figure 3). In silico DNA:DNA pairing between the genome of strain S2509T and the type strains of M. chokoriensis, M. inaquosa, M. taraxaci, and M. violae were 35.5\%, 36.4\%, 35.7\% and $36.0 \%$, respectively, values which are below the recommended $70 \%$ cut-off point for the delineation of prokaryotic species (Wayne et al. 1987). Similar results were observed when OrthoANI values were calculated for each pair, obtaining values under $90 \%$ between the new strain and the type strains of Micromonospora. These results confirm that the isolate represents a new taxon within the genus Micromonospora.

In conclusion, the phylogenetic, chemotaxonomic and morphological data demonstrate that strain S2509T represents a novel species of the genus Micromonospora, for which the name Micromonospora orduensis sp. nov. is proposed.

\section{Description of Micromonospora orduensis sp. nov.}

Micromonospora orduensis (or.du.en'sis. N.L. fem. adj. orduensis of or belonging to Ordu, from where the type strain was isolated).

Aerobic, Gram-staining positive actinomycete that forms extensively branched and nonfragmenting substrate mycelium. Aerial hyphae are absent. Spores are single, non-motile and have smooth surfaces. Good growth is observed on ISP2, ISP3, modified Bennett's and tryptic soy agar; moderate growth is observed on ISP6 and nutrient agar; poor growth is observed on ISP4, ISP5, ISP7 and Czapek's agar. The colour of the colonies varies from light orange to dark brown. Growth occurs from $\mathrm{pH} 5.0$ to 11, with an optimum at $\mathrm{pH} 7.2$, and from 28 to $40{ }^{\circ} \mathrm{C}$, with an optimum at $30^{\circ} \mathrm{C}$. The maximum $\mathrm{NaCl}$ concentration for growth is $3 \%(\mathrm{w} / \mathrm{v})$. Nitrate reduction is positive. Arbutin and aesculin are hydrolysed, but not allantoin or urea. Tween 40 and Tween 80 are degraded, but not adenine, casein, guanine, gelatin hypoxanthine, xanthine or xylan. D-Arabinose, L-arabinose, D-cellobiose, dextrin, D-fructose, D-galactose, D-lactose, D-mannose, D-maltose, L-rhamnose, D-ribose, 
D-sucrose and D-xylose are utilised as sole carbon sources but adonitol, dextran, inuline, D-mannitol, L-sorbose, D-sorbitol, xylitol are not. $\alpha$-Isoleucine, L-alanine, L-arginine, glycine, L-cysteine, L-hydroxyproline, L-methionine, L-phenylalanine, L-proline, Lserine, L-valine and are utilised as sole nitrogen sources, but L-histidine and L-tyrosine are not. The characteristic whole cell sugars are arabinose, glucose, rhamnose, ribose and xylose. The predominant menaquinones are MK-9(H8), MK-9(H6), MK-10(H8), MK9(H4), MK-10(H4) and MK-10(H6). The main polar lipids are diphosphatidylglycerol, phosphatidylethanolamine and phosphatidylinositol, and the main components of the cellular fatty acids are iso-C16:0, iso-C15:0 and 10-methyl C17:0. The G+C content of the genomic DNA of the type strain is $71.7 \mathrm{~mol} \%$.

The type strain, S2509T (=DSM 45926T = KCTC 29201T), was isolated from a Black Sea sediment sample collected along Melet River offshore of the southern Black Sea coast, Ordu, Turkey. The GenBank/EMBL/DDBJ accession numbers for the 16S rRNA gene and the genome of strain S2509T are KF494805 and VDFY00000000, respectively.

\section{Acknowledgements}

AV is gratefully acknowledge support from Ondokuz Mayis University (project no. PYO.

FEN. 1901.12.014) and the School of Biology (Newcastle University). LC thanks the University of Salamanca for a postdoctoral fellowship. Genome sequencing was provided by MicrobesNG (http://www.microbesng.uk), which is supported by the BBSRC (grant number BB/L024209).

\section{Author contributions}


AV, NS and HPK designed the study. AV isolated the strain and carried out phenotipic characterisation and single gene phylogenies. LC carried out chemotaxonomic analysis and genome sequencing and analysing. DC carried out scaning electron microscopy analysis and JMI carried out fatty acids determination. AV and LC wrote the manuscript. All authors have revised the manuscript.

\section{Compliance with ethical standards}

Conflict of interest The authors declare that they have no conflict of interest.

Ethical approval This article does not contain any studies with human participants and/or animals performed by any of the authors. The formal consent is not required in this study.

\section{References}

Ara I, Kudo T (2007) Two new species of the genus Micromonospora: Micromonospora chokoriensis sp. nov. and Micromonospora coxensis sp. nov., isolated from sandy soil. J Gen Appl Microbiol 53:29-37

Carro L, Nouioui I., Sangal V, Meier-Kolthoff JP, Trujillo ME, Montero-Calasanz MDC, Sahin N, Smith DL, Kim KE, Peluso P, Deshpande S, Woyke T, Shapiro N, Kyrpides NC, Klenk HP, Göker M, Goodfellow M. (2018). Genome-based classification of micromonosporae with a focus on their biotechnological and ecological potential. Scientific Reports, 8(1).

Carro L, Veyisoglu A, Cetin D, Igual JM, Klenk H-P, Trujillo ME, Sahin N (2019) A study of three bacteria isolated from marine sediment and description of Micromonospora globispora sp. nov. Systematic and Applied Microbiology 42:190-197

Chun J, Goodfellow M (1995) A phylogenetic analysis of the genus Nocardia with 16S rRNA gene sequences. Int J Syst Bacteriol 45:240-245

Collins CH, Lyne PM, Grange JM, Falkinham JO (2004) Microbiological Methods, 8th edn. London: Arnold 
Collins MD (1985) Isoprenoid quinone analysis in bacterial classification and identification. In: Goodfellow M, Minnikin DE, editors. Chemical methods in bacterial systematics. London: Academic Press 267-287

Cross T, Williams ST, Sharpe ME, Holt JG, editors (1989) The Actinomycetes II: Growth and examination of actinomycetes-some guidelines Bergey's Manual of Systematic Bacteriology Williams and Wilkins; Baltimore, USA: 19894:2340-2343

Felsenstein J (1981) Evolutionary trees from DNA sequences: a maximum likelihood approach. J Mol Evol 17:368-376

Felsenstein J (1985) Confidence limits on phylogeny: an approach using the bootstrap. Evolution 39:783-791

Garcia LC, Martínez-Molina E, Trujillo ME (2010) Micromonospora pisi sp. nov., isolated from root nodules of Pisum sativum. Int J Syst Evol Microbiol 60:331-337

Goodfellow M, Williams ST (1983) Ecology of actinomycetes. Ann Rev Microbiol 37:189-216

Gullo VP, McAlpine J, Lam KS, Baker D, Petersen F (2006) Drug discovery from natural products. J Ind Microbiol Biotechnol 33:523-531

Hayakawa M, Nonomura H (1987) Humic acid-vitamin agar, a new medium for selective isolation of soil actinomycetes. J Ferment Technol 65:501-509

Jensen PR, Gontag E, Mafnas C, Mincer TJ, Fenical W (2005) Culturable marine actinomycete diversity from tropical Pacific Ocean sediments. Environ Microbiol 7:1039-1048

Jones KL (1949) Fresh isolates of actinomycetes in which the presence of sporogenous aerial mycelia is a fluctuating characteristic. J Bacteriol 57:141-145

Kämpfer P, Kroppenstedt RM (1996) Numerical analysis of fatty acid patterns of coryneform bacteria and related taxa. Can J Microbiol 42:989-1005 
Kawamoto I (1989) Genus Micromonospora. Bergey’s Manual of Systematic Bacteriology 4:2442-2450

Kelly KL (1964) Inter-society color council-national bureau of standards color-name charts illustrated with centroid colors. US Government Printing Office, Washington, DC

Kimura M (1980) A simple method for estimating evolutionary rates of base substitutions through comparative studies of nucleotide sequences. J Mol Evol 16:111-120

Kluge AG, Farris FS (1969) Quantitative phyletics and the evolution of anurans. Syst Zool $18: 1-32$

Kroppenstedt RM (1985) Fatty acid and menaquinone analysis of actinomycetes and related organisms. In: Goodfellow M, Minnikin DE, editors. Chemical methods in bacterial systematics. London: Academic Press 173-199

Lechevalier MP, Lechevalier HA (1970) Chemical composition as a criterion in the classification of aerobic actinomycetes. Int J Syst Bacteriol 20:435-443

Lee I, Ouk Kim Y, Park SC, Chun J (2016) OrthoANI: ani mproved algorithm and softwa re for calculating average nucleotide identity. Int J Syst Evol Microbiol 66:1100-1103

Meier-Kolthoff JP, Göker M (2019) TYGS is an automated high-throughput platform for state-of-the-art genome-based taxonomy. Nature communications 10(1):2182

Mincer TJ, Jensen PR, Kauffman CA, Fenical W (2002) Widespread and persistent populations of a major new marine actinomycete taxon in the ocean sediments. Appl Environ Microb 68:5005-5011

Minnikin DE, O’Donnell AG, Goodfellow M, Alderson G, Athalye M, Schaal K, Parlett JH (1984) An integrated procedure for the extraction of bacterial isoprenoid quinones and polar lipids. J Microbiol Methods 2:233-241

Nash P, Krent MM (1991) Culture media. In: Balows A, Hauser WJ, Herrmann KL, Isenberg HD and Shadomy HJ (eds) Manual of clinical microbiology, 3th Edition, American Society for Microbiology, Washington DC, pp 1268-1270 
Ørskov J (1923) Investigations into the morphology of the ray fungi. Levin and Munksgaard, Copenhagen

Phongsopitanun W, Kudo T, Mori M, Shiomi K, Pittayakhajonwut P, Suwanborirux K, Tanasupawat S (2015) Micromonospora fluostatini sp. nov., isolated from marine sediment. Int J Syst Evol Microbiol 65(12):4417-23

Rusnak K, Troyanovich J, Mierzwa R, Chu M, Patel M, Weistein M (2001) An antibiotic with activity against gram-positive bacteria from the gentamicin-producing strain of Micromonospora purpurea. Appl Microbiol Biotechnol 56:502-503

Saitou N, Nei M (1987) The neighbor-joining method. A new method for reconstructing phylogenetic trees. Mol Biol Evol 4:406-425

Sasser M (1990) Identification of bacteria by gas chromatography of cellular fatty acids. Technical Note 101. Newark, DE: MIDI Inc

Shirling EB, Gottlieb D (1966) Methods for characterization of Streptomyces species. Int J Syst Bacteriol 16:313-340

Staneck JL, Roberts GD (1974) Simplified approach to identification of aerobic actinomycetes by thin-layer chromatography. Appl Microbiol 28:226-231

Tamura K, Stecher G, Peterson D, Filipski A, Kumar S (2013) MEGA6: molecular evolutionary genetics analysis version 6.0. Mol Biol Evol 30:2725-2729

Tan GYA, Ward AC, Goodfellow M (2006) Exploration of Amycolatopsis diversity in soil using genus-specific primers and novel selective media. Syst Appl Microbiol 29:557-569

Veyisoglu A, Carro L, Cetin D, Guven K, Spröer C, Pötter G, Klenk H-P, Sahin N, Goodfellow M (2016) Micromonospora profundi sp. nov., isolated from deep marine sediment. Int J Syst Evol Microbiol 66:4735-4743

Veyisoglu A, Carro L, Guven K, Cetin D, Sproer C, Schumann P, Klenk H-P, Goodfellow M, Sahin N (2016) Micromonospora yasonensis sp. nov., isolated from a Black Sea sediment. Antonie Van Leeuwenhoek 109:1019-1028 
Wayne LG, Brenner DJ, Colwell RR, Grimont PAD, Kandler O, Krichevsky MI, Moore LH, Moore WEC, Murray RGE, Stackebrandt E, Starr MP, Truper HG (1987) Report of the ad hoc committee on reconciliation of approachesto bacterial systematics. Int J Syst Evol Microbiol 37:463-464

Williams ST, Goodfellow M, Alderson G, Wellington EMH, Sneath PHA, Sackin MJ (1983) Numerical classification of Streptomyces and related genera. J Gen Microbiol 129:17431813

Yoon SH, Ha SM, Kwon S, Lim J, Kim Y, Seo H, Chun J (2017) Introducing EzBioCloud: a taxonomically united database of $16 \mathrm{~S}$ rRNA and whole genome assemblies. Int J Syst Evol Microbiol 67(5):1613-1617 
Table 1. Phenotypic properties of strain $\mathrm{S} 2509^{\mathrm{T}}$ and the closely related type strain M. chokoriensis DSM $45160^{\mathrm{T}}$. Strains: 1, S2509 ${ }^{\mathrm{T}} ; \mathbf{2}$, M. chokoriensis DSM 45160.$(+)$ positive, (-) negative.

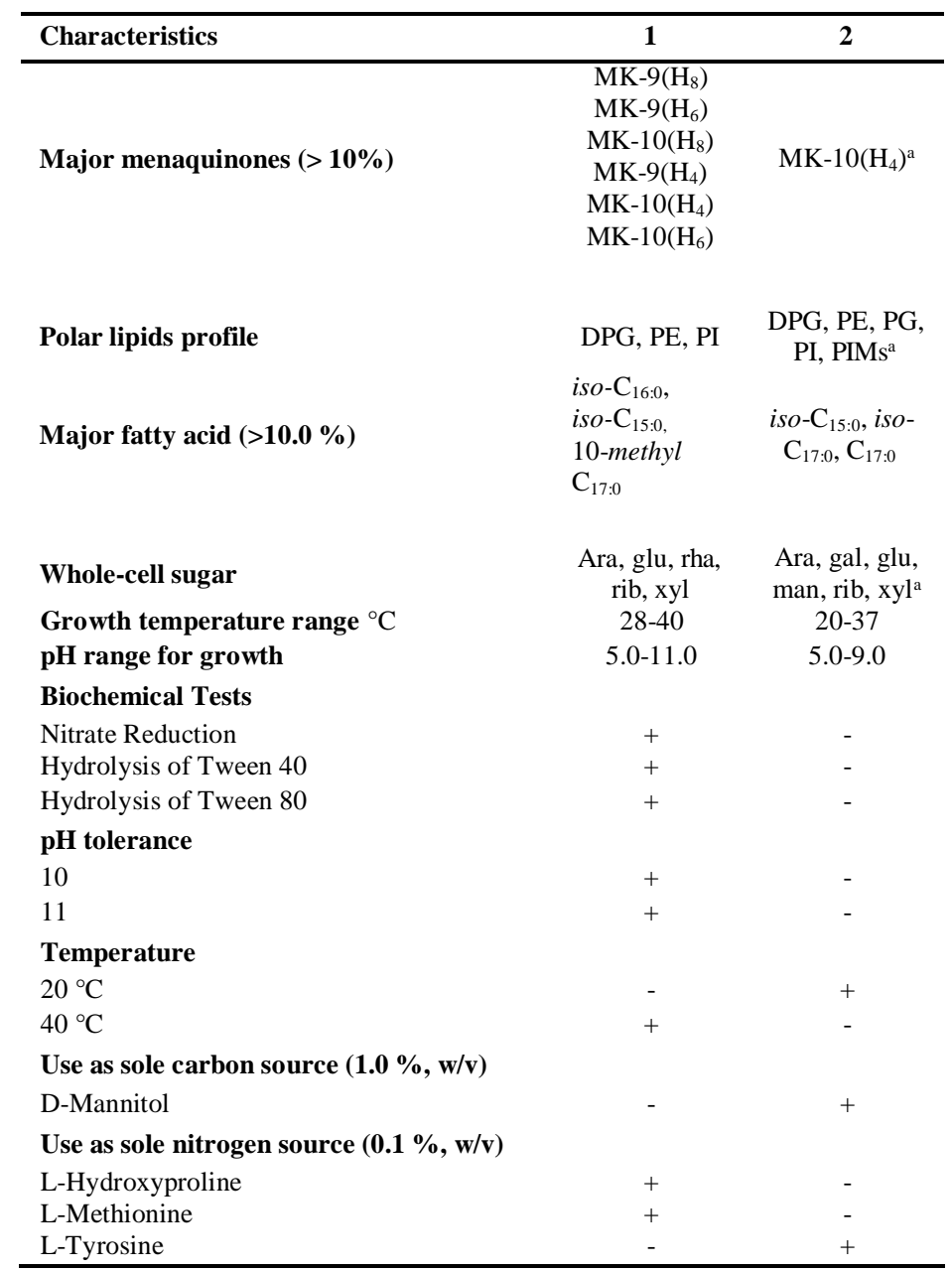

Abbreviations: +, positive; -, negative; DPG, diphosphatidylglycerol; PE, phosphatidylethanolamine; PG, phosphatidylglycerol; PI, phosphatidylinositol; PIM, phosphatidylinositol mannoside; Ara, arabinose; Gal,

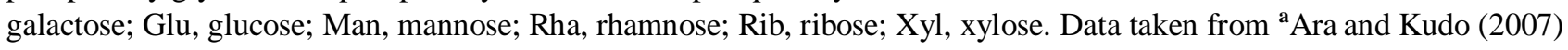


Table 2. Cellular fatty acid composition of strain $\mathrm{S} 2509^{\mathrm{T}}$ and the closely related type strain $M$. chokoriensis $\operatorname{DSM} 45160^{\mathrm{T}}$.

Strains: 1, S2509 $;$ 2, M. chokoriensis DSM 45160 ${ }^{\mathrm{T}}$. All cellular fatty acid composition data was determined in this study.

\begin{tabular}{|c|c|c|c|}
\hline Fatty acids & 1 & 2 & \\
\hline Saturated & & & 38 \\
\hline $\mathrm{C}_{15: 0}$ & - & 3.3 & \\
\hline $\mathrm{C}_{16: 0}$ & 1.0 & 1.4 & \\
\hline $\mathrm{C}_{17: 0}$ & 5.5 & 17.2 & 384 \\
\hline $\mathrm{C}_{18: 0}$ & 1.3 & - & \\
\hline $\mathrm{C}_{19: 0}$ & 0.3 & - & \\
\hline Saturated branched & & & 388 \\
\hline iso- $\mathrm{C}_{14: 0}$ & 1.2 & - & \\
\hline iso- $\mathrm{C}_{15: 0}$ & 17.0 & 42.2 & 391 \\
\hline iso- $\mathrm{C}_{16: 0}$ & 28.1 & 7.3 & \\
\hline iso- $\mathrm{C}_{17: 0}$ & 4.9 & 11.5 & \\
\hline iso- $\mathrm{C}_{18: 0}$ & 0.6 & - & 395 \\
\hline anteiso- $\mathrm{C}_{15: 0}$ & 5.0 & 7.6 & \\
\hline anteiso- $\mathrm{C}_{17: 0}$ & 7.9 & 3.2 & \\
\hline \multicolumn{3}{|l|}{ Unsaturated straight } & $n$ \\
\hline $\mathrm{C}_{17: 1 w 8 \mathrm{c}}$ & 5.9 & - & \\
\hline $\mathrm{C}_{17: 1 w 9 \mathrm{c}}$ & 0.4 & - & $\begin{array}{l}402 \\
411\end{array}$ \\
\hline $\mathrm{C}_{18: 1 w 9 \mathrm{c}}$ & 2.1 & - & \\
\hline \multicolumn{4}{|l|}{ Unsaturated branched } \\
\hline iso- $\mathrm{C}_{15: 1 \mathrm{G}}$ & 0.1 & - & 406 \\
\hline iso- $\mathrm{C}_{16: 1} \mathrm{H}$ & 0.9 & - & \\
\hline $\mathrm{C}_{18: 1} 2 \mathrm{OH}$ & 0.1 & - & 409 \\
\hline 10-methyl $\mathrm{C}_{17: 0}$ & 12.0 & 2.0 & \\
\hline 10-methyl $\mathrm{C}_{18: 0,}$, TBSA & 2.3 & - & \\
\hline *Summed features & & & 413 \\
\hline 3 & 0.3 & - & $a_{1}$ \\
\hline 6 & 0.6 & - & 416 \\
\hline 9 & 2.7 & - & \\
\hline
\end{tabular}

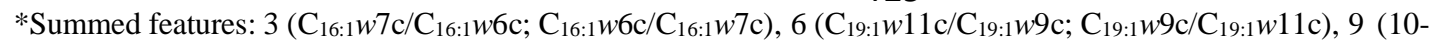
methyl $\mathrm{C}_{16: 0} /$ iso- $\mathrm{C}_{17: 1 w 9 \mathrm{c})}$ 


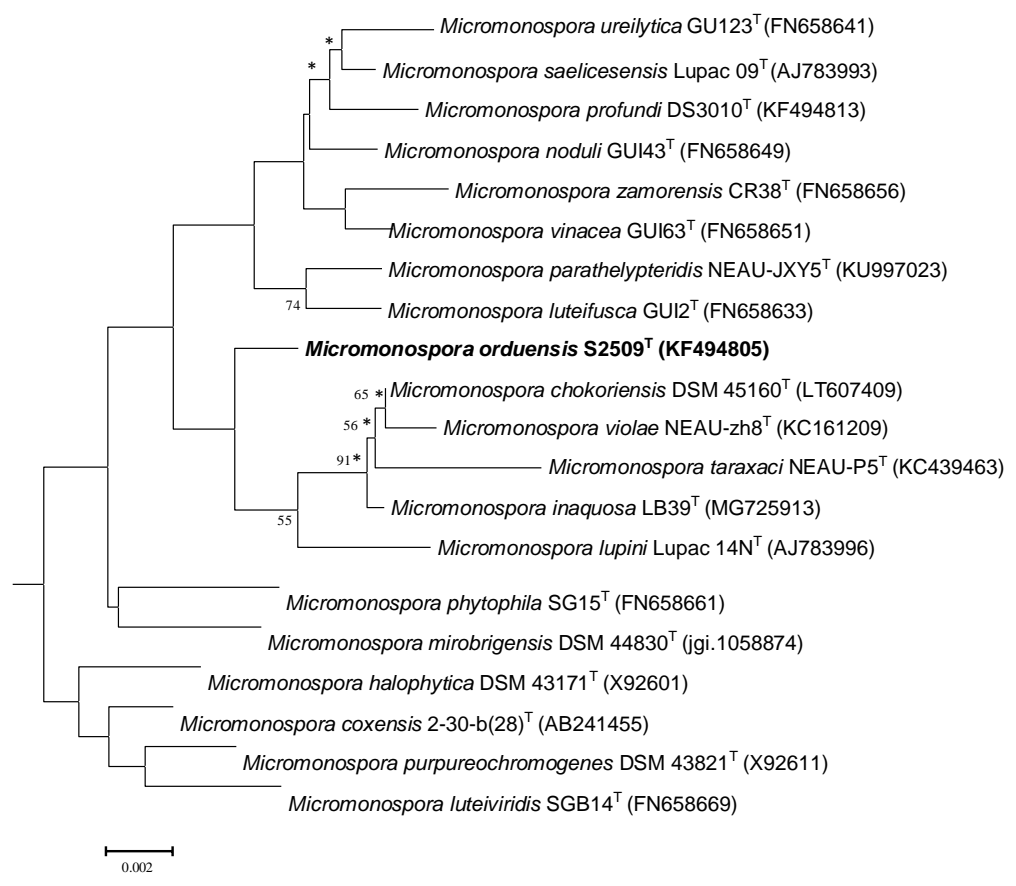

Fig. 1.

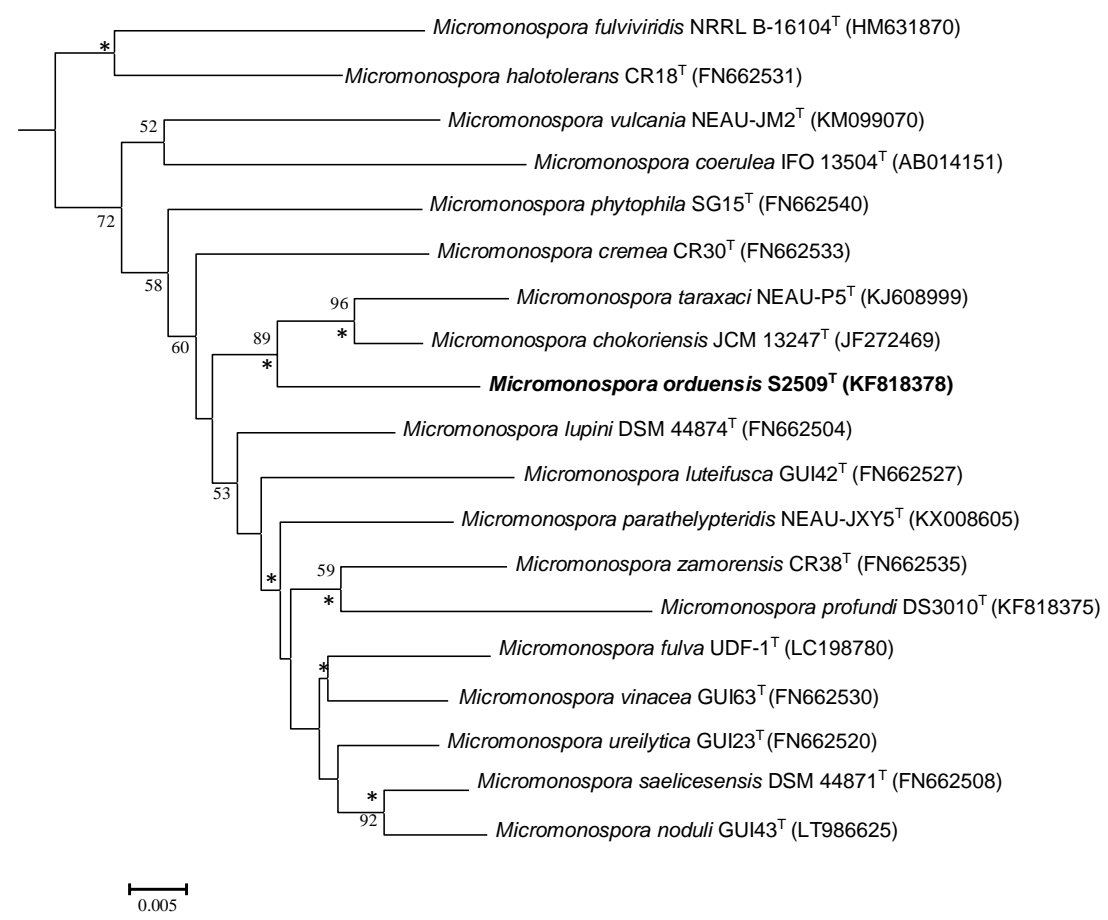

Fig.2. 
Tree scale: 0.01

G+C Content

$\square 70.6$

73.6

Genome size

Mbp
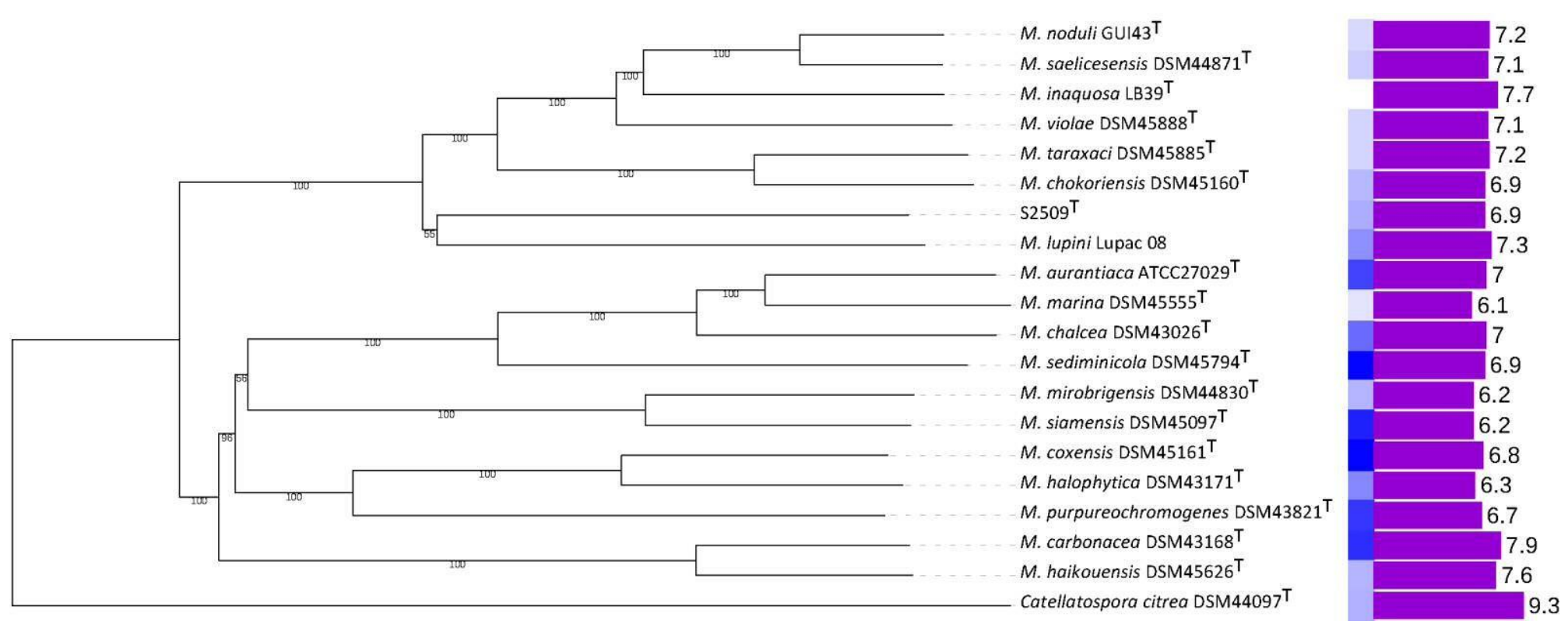

Fig. 3. 


\section{Figure captions}

Fig. 1. Neighbour-joining phylogenetic tree based on 16S rRNA gene sequences of strain $\mathrm{S} 2509^{\mathrm{T}}$ and amongst its phylogenetic neighbours. Asterisks $(*)$ indicate branches of the tree that were also recovered using the maximum-likelihood (Felsenstein 1981) and maximum-parsimony (Kluge and Farris 1969) tree-making algorithms. Numbers at the nodes indicate the levels of bootstrap support (\%); only values over $\geq 50 \%$ are shown. GenBank accession numbers are given in parentheses. Bar, 0.005 substitutions per site.

Fig. 2. Neighbour-joining phylogenetic tree based on 1131 bp gyrB gene sequences of strain $\mathrm{S} 2509^{\mathrm{T}}$ within the genus Micromonospora. Asterisks (*) indicate branches of the tree that were also recovered using the maximum-likelihood (Felsenstein 1981) and maximumparsimony (Kluge and Farris 1969) tree-making algorithms. Catellatospora citrea DSM $44097^{\mathrm{T}}$ (Ga0197484_11) was used as an outgroup. Bootstrap percentages based on 1000 replicates are shown; only values over $\geq 50 \%$ are shown. Bar, 0.02 substitutions per nucleotide position.

Fig. 3. Whole-genome sequence tree generated with TYGS for strain $\mathrm{S} 2509^{\mathrm{T}}$ and closely related species of the genus Micromonospora. Tree inferred with FastME from GBDP distances calculated from genome sequences. Branch lengths are scaled in terms of GBDP distance formula d5; numbers above branches are GBDP pseudo-bootstrap support values from 100 replications.

Supplementary Fig. S1. Scanning electron micrograph of strain $\mathrm{S} 2509^{\mathrm{T}}$ grown on N-ZAmine (DSMZ-medium 554) medium at $30{ }^{\circ} \mathrm{C}$ for 43 days.

Supplementary Fig. S2. The phospholipids of strain S2509 ${ }^{\mathrm{T}}$. Diphosphatidylglycerol (DPG), phosphatidylethanolamine (PE), phosphatidylinositol (PI), glycolipid (GL) and two unidentified phospholipids $\left(\mathrm{PL}_{1}-\mathrm{PL}_{2}\right)$. a, Using dragendorff's reagent; $b$, Using ninhydrin 
reagent; c, Using molybdenum blue reagent; d, Using molybdate phosphoric acid reagent. Solvents used were $\mathrm{CHCl}_{3}$ : $\mathrm{CH}_{3} \mathrm{OH}$ : distilled water $(65: 25: 4)$ for the first dimension and $\mathrm{CHCl}_{3}$ : glacial acetic acid: $\mathrm{CH}_{3} \mathrm{OH}$ : distilled water $(80: 12: 15: 4)$ for the second dimension.

Supplementary Fig. S3. Neighbour-joining phylogenetic tree based on 16S rRNA gene sequences of strain $\mathrm{S} 2509^{\mathrm{T}}$ and amongst its phylogenetic neighbours. Asterisks (*) indicate branches of the tree that were also recovered using the maximum-likelihood (Felsenstein 1981) and maximum-parsimony (Kluge and Farris 1969) tree-making algorithms.

Catellatospora citrea DSM $44097^{\mathrm{T}}$ (X93197) was used as out group. Numbers at the nodes indicate the levels of bootstrap support (\%); only values over $\geq 50 \%$ are shown. GenBank accession numbers are given in parentheses. Bar, 0.005 substitutions per site.

Supplementary Fig. S4. Maximum likelihood tree based on almost complete 16S rRNA gene sequences showing the position of strain $\mathrm{S} 2509^{\mathrm{T}}$ amongst its phylogenetic neighbours.

Supplementary Fig. S5. Maximum parsimony tree based on almost complete 16S rRNA gene sequences showing the position of strain $\mathrm{S} 2509^{\mathrm{T}}$ amongst its phylogenetic neighbours.

Supplementary Fig. S6. Neighbour-joining phylogenetic tree based on 1131 bp gyrB gene sequences of strain $\mathrm{S} 2509^{\mathrm{T}}$ within the genus Micromonospora. Asterisks (*) indicate branches of the tree that were also recovered using the maximum-likelihood (Felsenstein 1981) and maximum-parsimony (Kluge and Farris 1969) tree-making algorithms.

Catellatospora citrea DSM $44097^{\mathrm{T}}(\mathrm{Ga0197484} 11)$ was used as an outgroup. Bootstrap percentages based on 1000 replicates are shown; only values over $\geq 50 \%$ are shown. Bar, 0.02 substitutions per nucleotide position.

Supplementary Table S1. Cultural characteristics of the novel strain $\mathrm{S} 2509^{\mathrm{T}}$ and closely related type strain. 


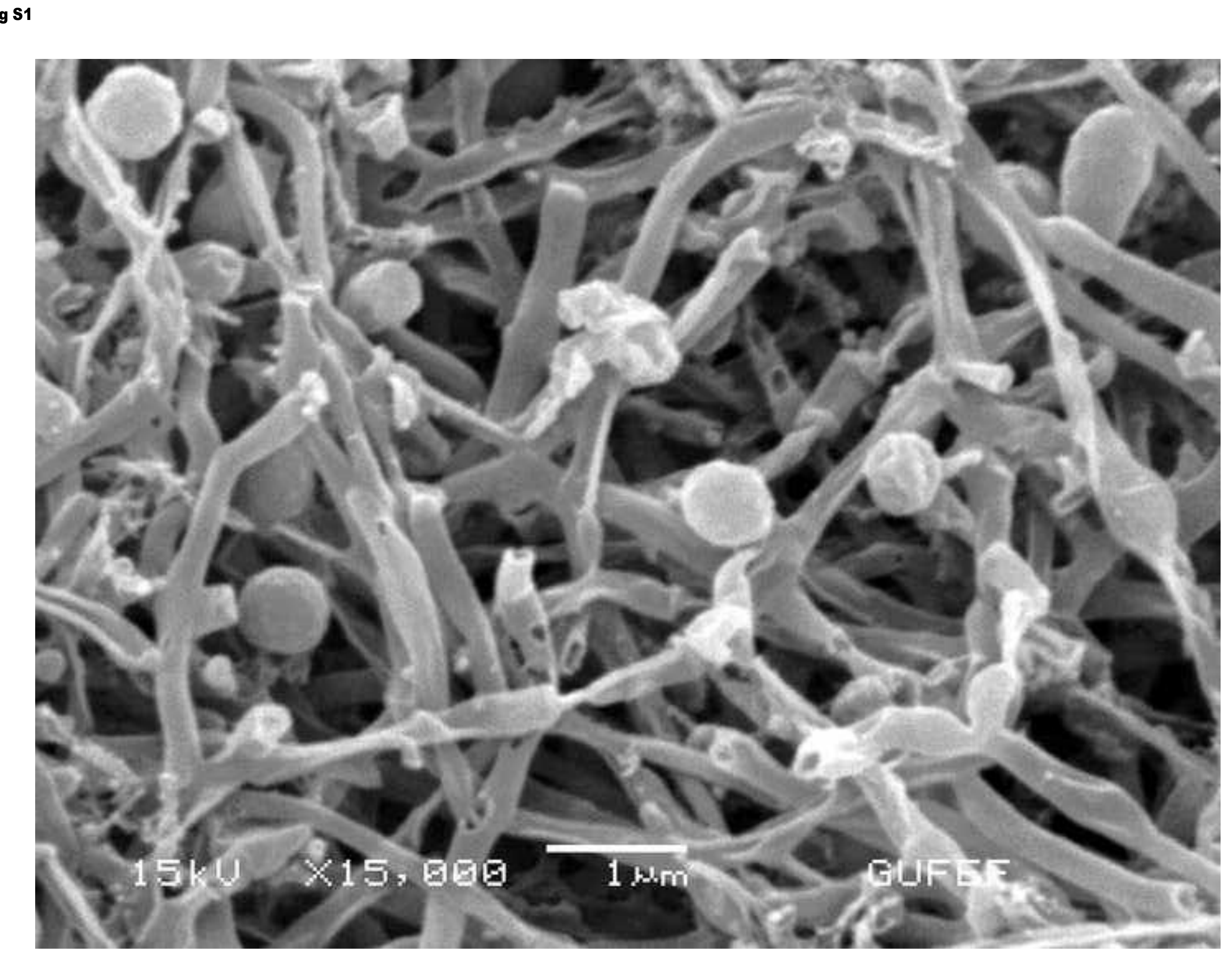

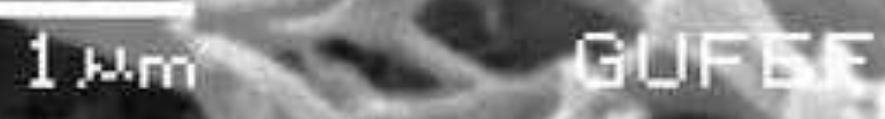
a

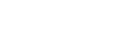




\section{DSM 45926}

\section{Dragendorff}

56 in 45726

a

$\mathrm{GL}$

Molybdenum blue

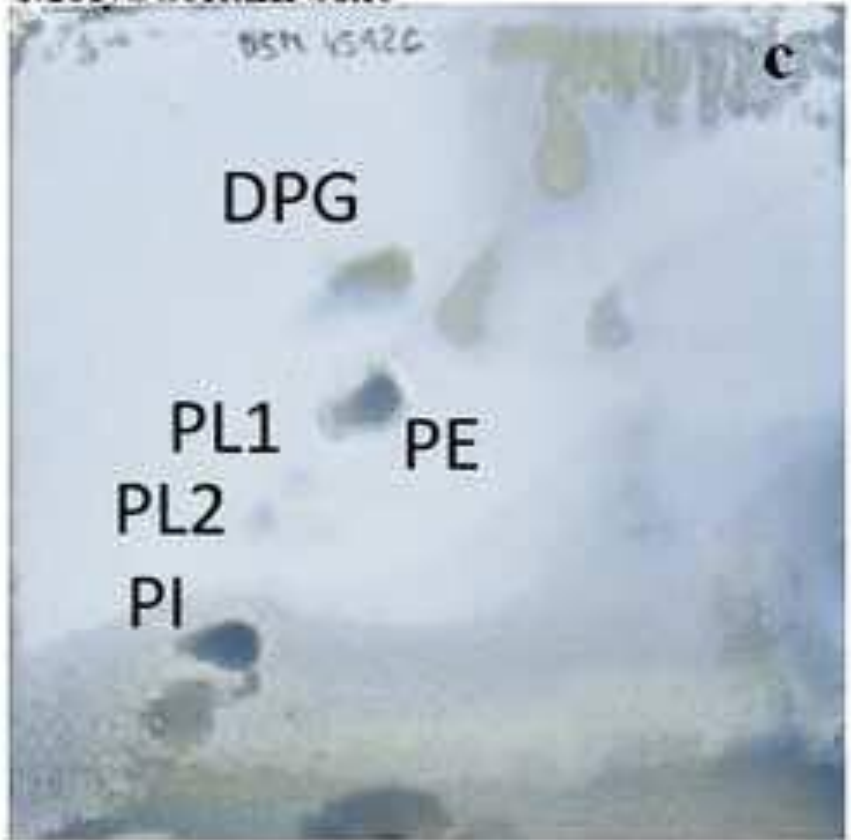

Ninlyydrin

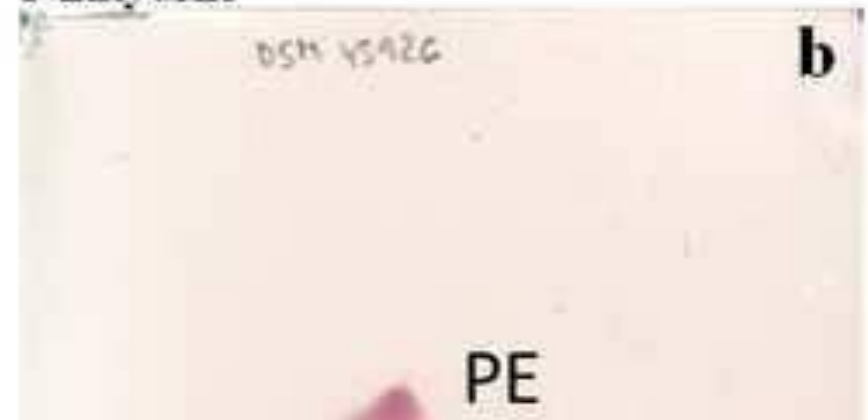

Molybdate phosphoric acid

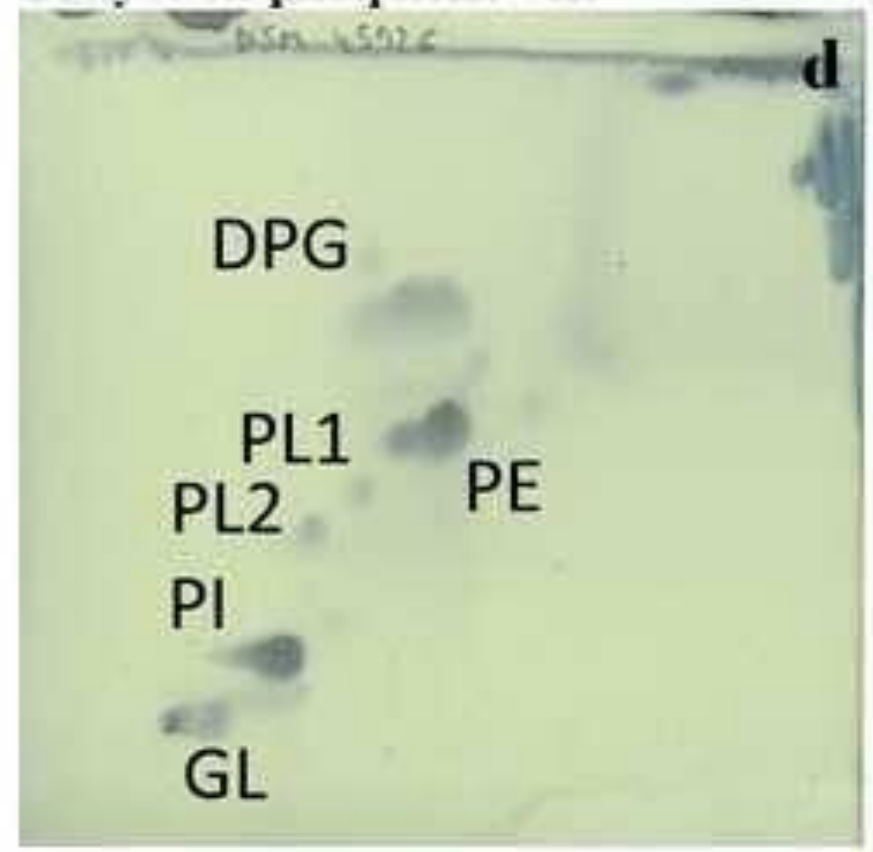




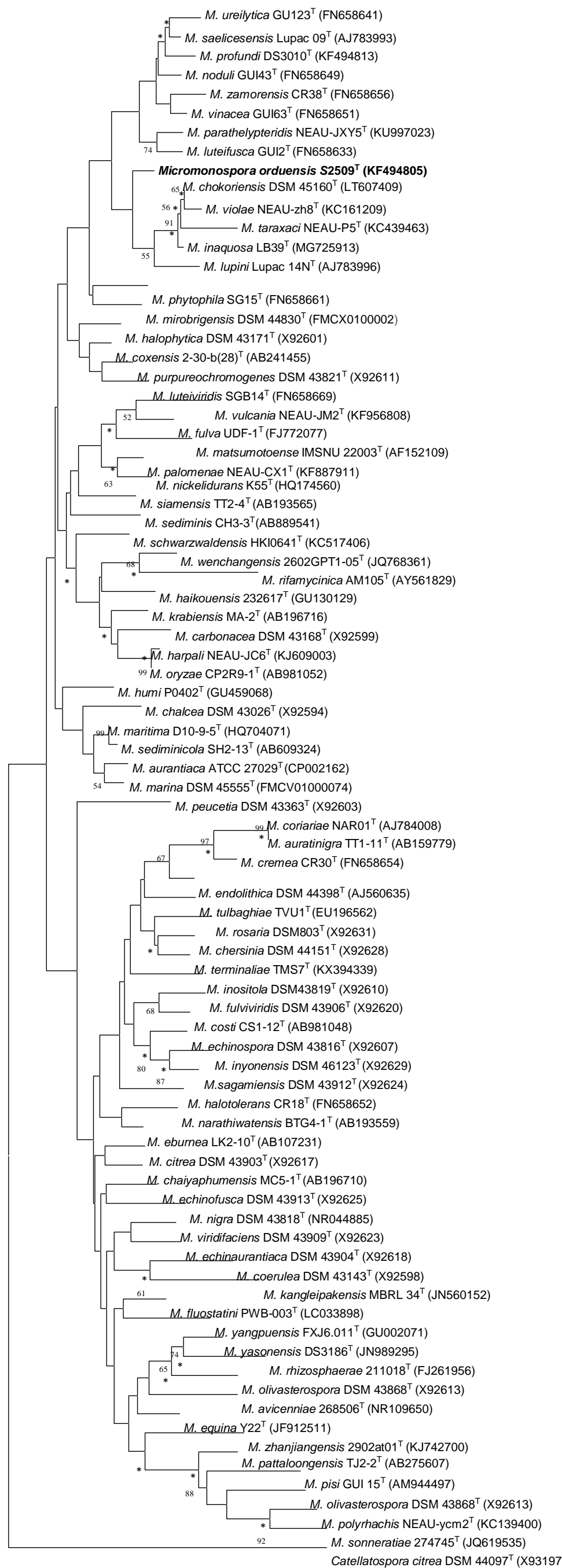

Fig. S3. 


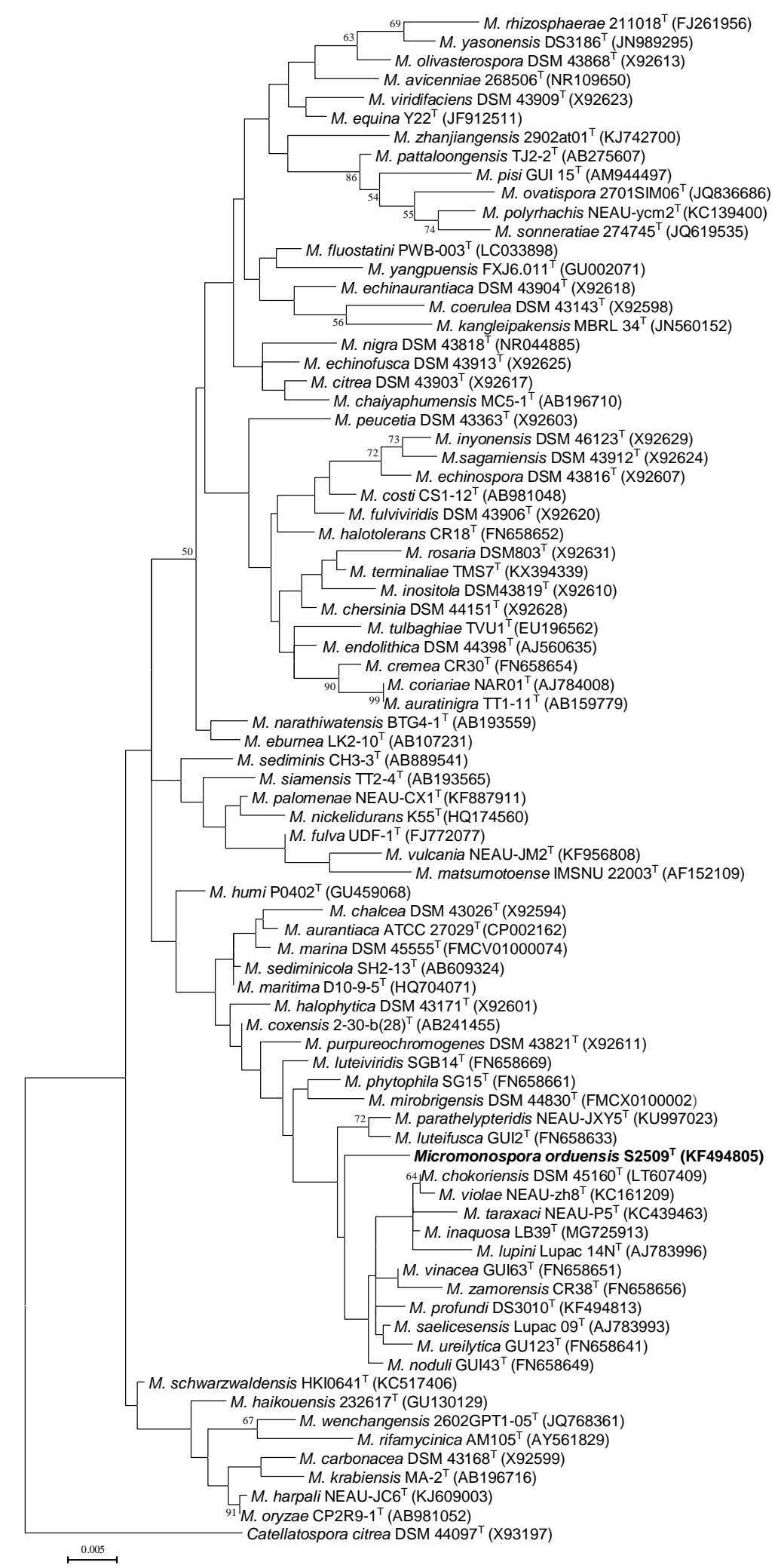

Fig. S4 


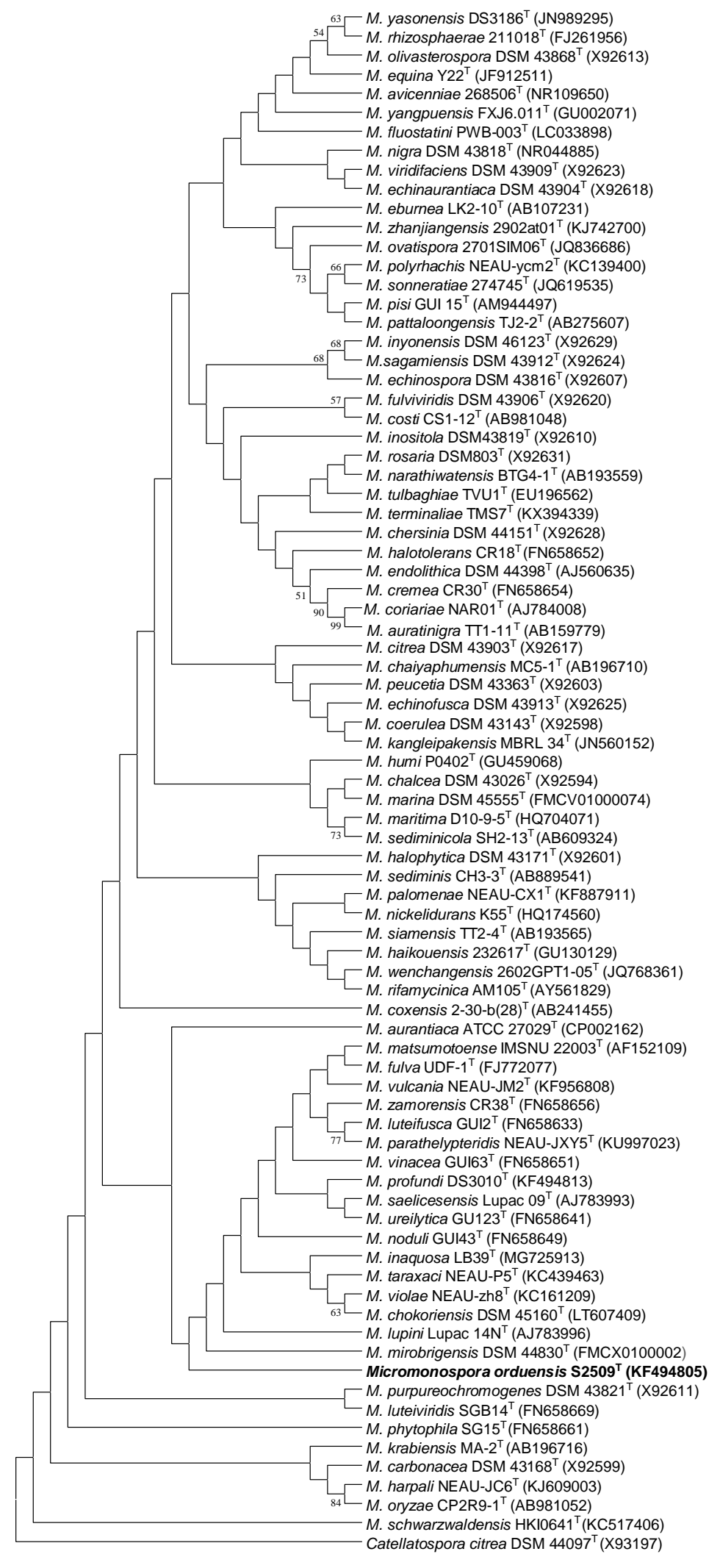

Fig. S5 


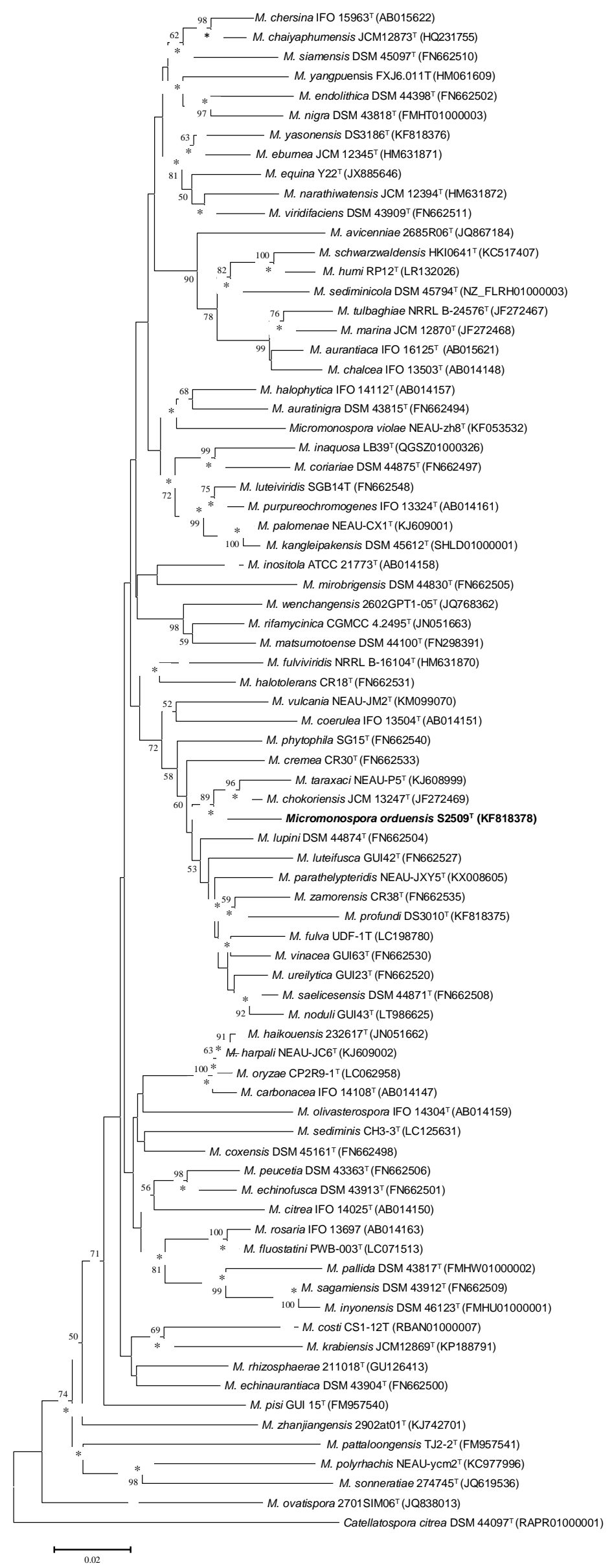

$98-$ M. chersina IFO $15963^{\top}$ (AB015622)

* — M. chaiyaphumensis JCM12873Т (HQ231755)

M. yangpuensis FXJ6.011T (HM061609)

M. endolithica DSM 44398' (FN662502)

r - M. auratinigra DSM 43815 (FN662494)

$-99$

$75-M$. luteiviridis

M. Kange

M. phytophila SG15 (FN662540)

uensis S2509 ${ }^{\top}$ (KF818378)

fulva UDF-1T(LC198780)

vinacea GUl63T (FN662530)

M. ureilytica GUI23 ${ }^{\top}$ (FN662520)

${ }^{\top}(\mathrm{AB} 014147)$

M. peucetia DSM 43363'(FN662506)

(FMHW01000002)

CS1-12T (RBAN01000007) 
sTable S1. Cultural characteristics of the novel strain $S 2509^{\mathrm{T}}$ and closely related type strain.

\begin{tabular}{|l|l|l|l|l|}
\hline & Micromonospora sp. S2509 & M.chokoriensis DSM 45160 \\
\hline Media & Growth & Color of colony* & Growth & Color of colony* \\
\hline Yeast extract-malt extract agar (ISP 2) & Good & Dark orange & Good & Dark brown \\
\hline Oatmeal agar (ISP 3) & Good & Dark brown & Moderate & Light orange \\
\hline Inorganic salt starch agar (ISP 4) & Poor & Light orange & Moderate & Light orange \\
\hline Glycerol asparagine agar (ISP 5) & Poor & Light orange & Poor & Colorless \\
\hline Pepton-yeast extract iron agar (ISP 6) & Moderate & Light orange & Poor & Orange yellow \\
\hline Tyrosine agar (ISP 7) & Poor & Dark orange & Poor & Light yellow \\
\hline Modified Bennett's agar & Good & Light orange & Good & Dark brown \\
\hline Czapek's agar & Poor & Light orange & Good & Brown \\
\hline Nutrient agar & Moderate & Light orange & Poor & Orange yellow \\
\hline Tryptic soy agar (TSA) & Good & Light orange & Moderate & Light brown \\
\hline
\end{tabular}

* The ISCC-NBS color charts were used to determine the designations of colony color (Kelly 1964).

No diffusible pigments were observed on any of the tested media 